\title{
SATELLITE-BASED MAPPING OF ABOVE-GROUND BLUE CARBON STORAGE IN SEAGRASS HABITAT WITHIN THE SHALLOW COASTAL WATER
}

\author{
Dalhatu Aliyu Sani ${ }^{1,2,3}$, Mazlan Hashim ${ }^{1,2, *}$ \\ ${ }^{1}$ Geoscience \& Digital Earth Centre (INSTEG), Research Institute for Sustainable Environment (RISE), Universiti Teknologi \\ Malaysia, Johor Bahru, Malaysia \\ ${ }^{2}$ Faculty of Built Environment \& Surveying, Universiti Teknologi Malaysia, Johor Bahru, Malaysia \\ ${ }^{3}$ Department of Geography, Yusuf Maitama Sule University, Kano, Nigeria \\ *corresponding author: mazlanhashim@utm.my
}

KEYWORDS: Blue Carbon, Seagrass, STAGC, Landsat 7 ETM+, BRI, DII

\begin{abstract}
:
These Mapping and estimation of seagrass total above-ground carbon (STAGC) using satellite-based techniques are required to fasttrack the achievement of the 2020 agenda on Sustainable Development Goals (SDG) $14^{\text {th }}$. This attainment is possible as seagrass habitats provide a critical coastal ecosystem for storing blue carbon stock, sediment accumulation, fisheries production and stabilisation of coastal environment. However, seagrasses are generally declining across the globe due to anthropogenic disturbance, resulting in a prolonged growth rate of seagrasses that varies according to the species compositions. Therefore, this study aims at mapping and estimation of seagrass total above-ground carbon (STAGC) using Landsat ETM+ in the coastline of Penang. These satellite images were calibrated with Bottom Reflected Index (BRI) and Depth Invariant Index (DII) to compare the estimate of the STAGC for more accuracy. The leaving radiances of the seagrass were correlated with the corresponding in-situ measurements to predict seagrass carbon. This established relationship with BRI image shown a healthy correlation with STAGB $\left(\mathrm{R}^{2}=0.992, \mathrm{p} \leq\right.$ $0.001)$. Whereas the STAGB versus DII relationship has less accuracy $\left(R^{2}=0.955, p \leq 0.01\right)$, adjusted $R^{2}=0.980$ and 0.978 were recorded for both BRI and DII STAGC estimate using the logistic model. Therefore, careful management of blue carbon stock is essential, as this study shall contribute to achieving targets 14.2 and 14.5 of SDG $14^{\text {th }}$ by the United Nations.
\end{abstract}

\section{INTRODUCTION}

\subsection{Background of the Study}

Satellite-based mapping and estimation of seagrass total aboveground carbon (STAGC) are crucially required. With seagrass habitats as coastal flowering vegetation, which holds essential ecological roles in coastal ecosystems. The seagrasses are considered essential ecosystem due to the extensive meadows they form, which support high biodiversity. These habitats also provide a critical coastal ecosystem for storing blue carbon stock, sediment accumulation, fisheries production and stabilisation (Traganos et al., 2018). They generally contribute to the ocean ecosystems services by providing a vital nursery area for several species that support fisheries and adjacent habitats (Tan et al., 2016).

The seagrass meadows ecosystem functions comprise genetic variability maintenance, coastal environment resilience by protecting from erosion, as well as carbon sequestration via removing carbon dioxide $\left(\mathrm{CO}_{2}\right)$ from the atmosphere and storing it as an organic matter (Misbari and Hashim, 2016). Their higher productivity qualifies them a disproportionate impact on ocean great primary productivity, usually producing substantially more organic carbon (OC) than the seagrass habitat requires (Hossain et al., 2015). Seagrass carbon storage is effective removal of $\mathrm{CO}_{2}$ from the atmosphere and ocean pools, which plays an essential role in climate change mitigations (Sani and Hashim, 2018).

However, seagrasses are mainly declining due to anthropogenic disturbance, resulting in a prolonged growth rate that varies according to the species compositions. The $20^{\text {th }}$ century, and primarily since the 1940 s, the seagrass habitats losses have been detected in various realms across the globe as a result of industrial impacts, boating, construction, dredging, overfishing, mining, and rising sea levels. In Malaysia sixteen widely distributed seagrass species exists in both subtidal and intertidal environment, shoals and semi-enclosed lagoons along the coastline of Malaysia. They are providing massive ecosystem services, while frequently experiencing a gradual decline as at the global level. This continued deterioration of local seagrass is due to growth in population and economic advancements.

Currently, studies on seagrass blue carbon stock mapping and estimations of STAGC using satellite-based remote sensing (RS) are limited (Hashim et al., 2014). Therefore, an urgent need for regional and continental mapping and estimation of seagrass carbon stock is required. Indeed, this habitat may perhaps function as an indicator for climate change mitigation, offering valuable information that will be useful for coastal health management. It also provides conservations of related habitats within the investigated sites such as coral reefs and mangrove forest (Sani and Hashim, 2018).

Hence, cost-effective techniques for seagrass blue carbon stock mapping and estimation is required, to replace conventional methods and overcome the confines available researchers and resources for such evaluation. Satellite remotely sensed data had been employed successfully, to detects, map, and estimate seagrass above-ground biomass (Misbari and Hashim, 2016). Percentage cover (Kovacs et al., 2018) and change detection in seagrass above-ground biomass estimation (Misbari and Hashim, 2014). Single species of seagrasses have similarly been spectrally detected and mapped by employing 
hyperspectral RS data (Lyons et al., 2011). RS seagrasses maps of large-scale areas with high accuracy has been realised within less cleared and cleared water via Depth Invariant Index (DII) and Bottom Reflected Index (BRI) (Misbari and Hashim, 2016; Poursanidis et al., 2018; Traganos, et al., 2018).

Despite the efforts invested by researchers, however, there are no documented studies on the seagrass total above-ground carbon stock using the satellite-based approach in the entire Penang coastline and these results to a vacuum in complying with United Nation's convention on climate change. Therefore, this study employed the satellite-based RS techniques to mapped and estimated seagrass total above-ground carbon stocks using BRI and DII in Penang coastline of Peninsula Malaysia (PM). Similarly, the STAGC quantified from BRI and DII were compered for more accuracy. The estimate was successfully achieved using Landsat ETM+, which was realised by upscaling the study sample sites. It is crucial to report the seagrass total above-ground carbon stock for supporting the realisation of sustainable developments goal's targets 14.2, and 14.5 establish by the United Nations.

\section{MATERIALS AND METHOD}

Seagrass total aboveground carbon data was obtained from the seagrass habitats occurring in the coastline Penang of PM. The study area covers about $131,590 \mathrm{~km}^{2}$ of the total land area, as presented in Figure 1. Penang state is in the north-western coastline of PM, to the northern and eastern part bounded by Kedah state. The southern part is boarder by Perak state, similarly at the western side by the Straits of Malacca, as well as Sumatra of Indonesia. Penang encompasses the Penang Island, which has an area coverage of approximately $285 \mathrm{~km}^{2}$, and a coastal strip in the mainland known as Province Wellesley. Gazumbo Island is sandbank located in the eastern coastline $\left(5^{\circ} 21^{\prime} \mathrm{N}, 100^{\circ} 19^{\prime} \mathrm{E}\right)$, near the Penang Bridge where the in-situ seagrass samples were collected, up-scaled to map the seagrass total aboveground biomass of the entire Penang coastline.

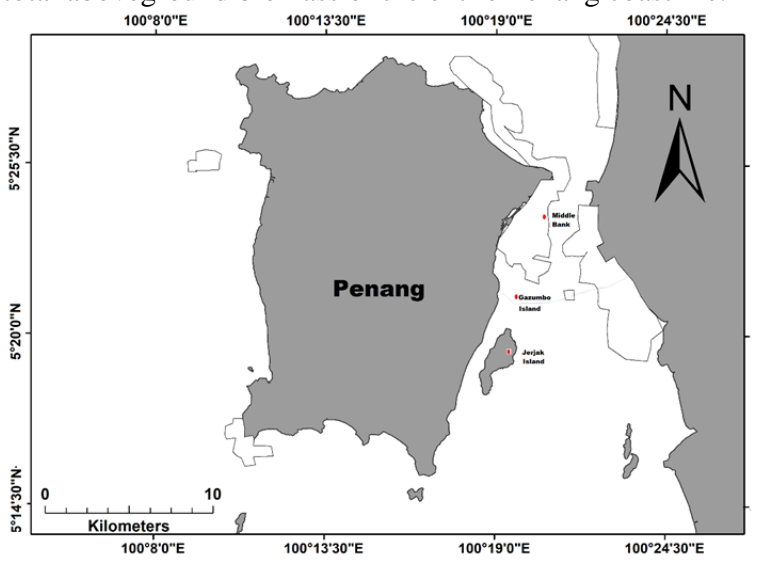

Figure 1. Seagrass boundaries along the study area.

\subsection{Materials}

Two principal material sets were employed in this study, precisely the satellite-based RS data and field measurements via in-situ observations utilised for ground-truthing. This groundtruthing is divided into two independent mutual sets for induction and deduction of the seagrass modelling. The Landsat 7 ETM+ data were used to estimate STAGC. The image was enclosed with minimum cloud cover inclined by monsoon seasons (see Table1). The field samples gathering in
2017 was performed in Gazumbo Island, which was extended to cover the whole seagrass meadows occurring within the coastline of Penang state. Furthermore, hydrographical charts obtained from the "Malaysian National Hydrographic Centre" was used for getting the depth.

Table 1. Description of the information on Landsat 7 ETM+ images employed for this study

\begin{tabular}{|c|c|c|c|c|c|}
\hline No. & Scene ID & $\begin{array}{c}\text { Date of } \\
\text { Acquisition }\end{array}$ & $\begin{array}{l}\text { Loca- } \\
\text { tion }\end{array}$ & Monsoon & $\begin{array}{c}\text { Cloud } \\
\text { Coverage } \\
(\%)\end{array}$ \\
\hline 1. & $\begin{array}{l}\text { LE71280 } \\
56201701 \\
\text { 0EDC00 }\end{array}$ & $2017-01-10$ & $\begin{array}{l}\text { Penan } \\
\mathrm{g}\end{array}$ & $\mathrm{NE}^{*}$ & 6 \\
\hline
\end{tabular}

Note: *seagrass possibly not affected by monsoon

\subsection{Data Processing}

The two major stages (as shown in Figure 2) comprise three data processing phases were observed in this study. These phases involve a) pre-processing of data comprising geometric correction, radiometric correction, and atmospheric correction of satellite image; b) seagrass occurrence mapping; and c) estimation of STAGC from the derived seagrass boundary (distribution map). Figure 2 demonstrates the flowchart of the entire three data processing phases. The tasks involved in data processing were achieved through processing software of digital image ArcMap version 10.4 and ENVI version 5.0.

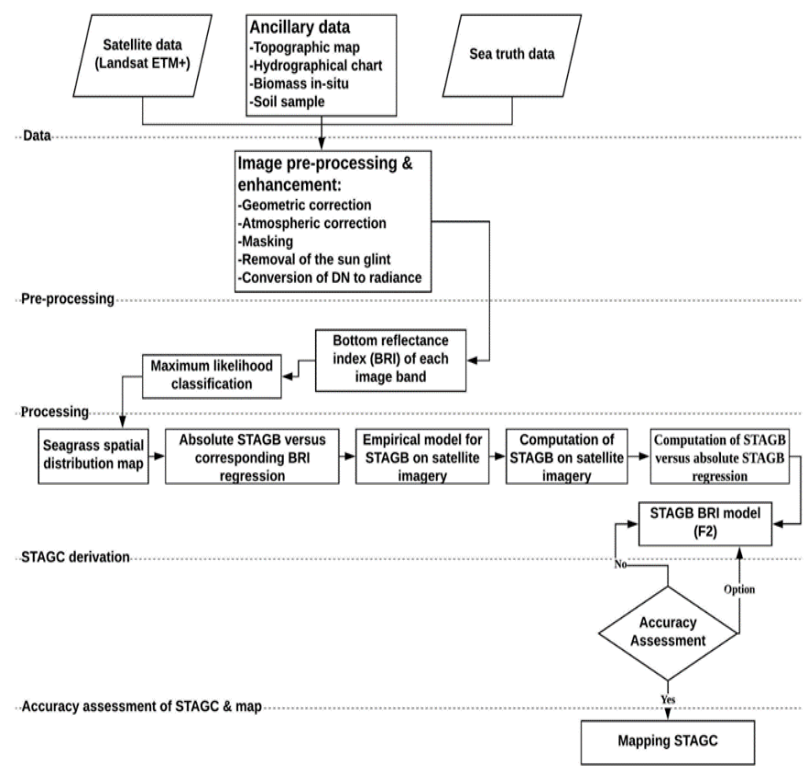

Figure 2. STAGC estimation flow chart employing BRI.

To achieve the estimate of seagrass carbon in any of its biophysical components precisely STAGC using satellite images. Specific processes were observed, starting from in-situ seagrass measurements to satellite data acquisition. Similarly, pre-processing and processing of the satellite imageries, biomass estimation, and biomass to carbon conversion using 0.34 an existing conversion factor was also observed. Those mentioned above were well explained in a publication that estimates the seagrass biomass changes along Straits of Johor, in Merambong, PM (Misbari and Hashim, 2016). Although this study only used two seagrass retrieval after the water column corrections using BRI and DII, which are needed for understanding the dynamics of seagrass carbon stocks estimation. 


\subsection{Seagrass in-situ Sampling Method}

Seagrasses occurrences around the study location were observed according to the tidal height, considered a challenges task in seagrass data gathering. Thirty (30) transects were established randomly in the sample locations (Gazumbo island Penang state), precisely within the shoal as well deep-water border. Similarly, quadrates were linearly placed and moved in every $5 \mathrm{~m}$ along a 50 to $100 \mathrm{~m}$ transects line, placed in the seagrass meadows. The entire location of the sample points was marked on the images of ETM+. GPS (Garmin) handheld was employed for recording each point, most significantly at the starting as well as the ending points of the overall transect lines. For estimating seagrass mixed species, 72 STAGB samples were harvested within the sample location via a $0.25 \mathrm{~m}^{2}$ quadrate, representing one-quarter of a full quadrate, which ranges from $100 \%$ to < than $10 \%$ quadrate coverage of seagrass. These samples were cleaned by applying the formalin solution together with clean water before proceeding to dry via oven for about a minimum of 48 hours and at $900 \mathrm{C}$, till no more weight loss was documented. STAGC samples were weighed using an electronic scale. Therefore, the samples recorded were correlated with the corresponding BRI for mapping and estimation of STAGC.

\subsection{Applying Water Column Correction Methods to Improve Accuracy in Seagrass Model}

It is necessary to measure light attenuation and correct the effects of the water column on benthic reflection utilised in applications, which encompass the SAV production and mapping of seagrass ecosystem (Klemas, 2013a, 2013b). The most common method used for water column correction is that of the Lyzenga's (Lyzenga, 1981; Maritorena, 1996). Lyzenga (1978), this conveyed the correlation amongst radiance with bottom reflectance via the following equation:

$$
L_{i}=L_{d, i}+a_{i} r_{i} \exp \left(-K_{i} g Z\right),
$$

where

$L_{i}$ describes the radiance within bandi. $L_{d, i}$ stands for the radiance average, which was recorded in deep-water in band (meaning external reflection obtained from the surface of water and scattering from the atmosphere). $a_{i}$ always constant, comprise of solar irradiance, atmospheric transmittance, water surface, and the radiance reduction. All mentioned occurred as a result of refraction in the water surface. $r_{i}$ stands for bottom surface reflectance, whereas, $\mathrm{Ki}$ refers to the efficient water attenuation coefficient $\left(\mathrm{m}^{-1}\right)$ of bandi. $g$ implies the geometric factor accounting for the path length via the water, $Z$ stands for the water depth $(\mathrm{m})$, and exp indicate the exponential. As further suggested by Lyzenga (1978) that a depth-invariant index (DII) calculation should be enabled to remove scattering of light. Absorption effects in both water body and atmosphere can also be calculated, as expressed in equation (2):

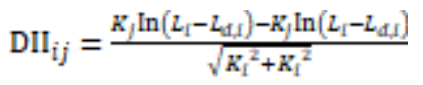

where subscripts of $\mathrm{i}$ and $\mathrm{j}$ correspond to two distinct satellite bands and refer to the natural logarithm. This DII is recognised to be effective in correcting less turbid water (clear water) such as type I and II waters (Bukata et al., 2018), however inefficient when there is less clarity of the water (Sagawa et al., 2010). Hence, to improve the accuracy of coastal mapping Sagawa et al. (2010) suggested for an alternative model as "bottom reflectance index (BRI)", which can be expressed through the following equation:

$$
B R I=\frac{(L i-L s i)}{[\exp (-K i g Z)]}
$$

Through substituting the numerator of equation (3) via $a_{i} r_{i} \exp$ $\mathrm{KigZ}$ of equation (1), therefore, the BRI could be re-arranged as equation (4):

$$
\mathrm{BRI}_{i j}=a_{i} r_{i}
$$

Where $a$ and $r$ refer to as in equation (1), with this development, BRI can proficiently be used in type II and III coastline. This achievement enables the comparison of more than only the proportions in reflectance distinction.

\subsection{Seagrass Total Blue Carbon Stock Derivation Using Satellite-based and In-Situ Data}

The STAGC was derived using BRI and DII models for retrieving submerged seagrass. The utilisation of these two models is to prove their efficiency in carbon stock estimation. Therefore, the most effective model for seagrass assessment is BRI; with that reason, the model is expressed as followed:

The model BRI was termed $f_{l}$, which was produced from the values of BRI on the satellite imagery. This model was used for estimating the STAGC by establishing a relationship between the BRI values and STAGB in-situ measurement using the logistic model. The new extracted values of the image were derived through applying the STAGB model with the STAGB in-situ, were employed for accuracy assessment (RMSE). The accuracy was achieved to ensure the precise measurement of the STAGC within the study site.

$$
\text { Seagrass } S T A G B=f_{l}(B R I) X C \text {. }
$$

where:

$S T A G B=$ seagrass total above-ground biomass,

$f_{l}(B R I)=$ function of STAGB in term of BRI, and

$C=$ a conversion factor of 0.34 (34\% of the biomass in seagrass is carbon) to convert biomass to carbon, Therefore, STAGC is the function of BRI.

\section{RESULTS AND DISCUSSION}

The main results presented by this study comprised a) mapping the spatial extent of seagrass meadows and b) quantification of the total aboveground seagrass carbon using BRI and DII in the coastline of Penang. The motivation that trigged the seagrass carbon estimation is to comply with the UNFCCC conversion, which mandates all member state to report the inventory of their carbon stocks.

\subsection{Mapping the Spatial Extent of Seagrass Aboveground Carbon}

Before the estimation of seagrass blue carbon stored in aboveground, the mapping of the spatial extent, it is necessary 
to identify the boundaries of the seagrass occurrence within the study area. Carbon stocks estimation is generally measured as the percentage of carbon stores in blue carbon habitats. This proportion is typically described in metric tonnes of carbon per hectare (Mt $/ \mathrm{ha}^{1}$ ) of an identified depth (Kroeger et al., 2017). Hence, the seagrasses in the study location were spatially mapped, and their proportion was estimated. The said tasks were realised via selecting a suitable logistic model, which was employed for establishing a relationship between BRI and STAGB. The correlations were successfully achieved, and carbon contents of the STAGC, as well as mapping, were realised.

The spatial extent of the seagrass meadows was mapped, and their boundaries were identified based on the sample point of in-situ measurement. Likewise, the seagrass presence through utilising maximum likelihood classification was detected (Table 2). In Gazumbo the sample area, 1,342.17ha of STAGC were discovered, whereas $0.4 \mathrm{MtC} / \mathrm{ha}^{1}$ was recorded as the contents of STAGC in aboveground seagrass pools. The predicted and derived carbon contents were correlated to ensure accuracy and for validating the seagrass results.

Table 2. Summary of seagrass locations using MLC.

\begin{tabular}{llll}
\hline \multicolumn{1}{c}{ Classes } & Gazumbo & $\begin{array}{c}\text { Proportion of extent } \\
(\%)\end{array}$ \\
\hline Deepwater & 181845 & 38 \\
Mud & 126862 & 27 \\
Seagrass & 163528 & 35 \\
Total extent $=$ & 472235 & & \\
\hline
\end{tabular}

For determining the seagrass occurrences, values of pixel were converted into BRI. The Landsat ETM+ 2017 corrected water column's bands were classified for spatially mapping the distribution of seagrass meadow. MLC was employed for supervised classification due to the well-distribution and adequate sampling data for training and assigning individual pixel into the possible corresponding substrate classes according to probability density function. The classification method is proven as the best in categorically classifying underlying substrate features. Before this classification exercise, training areas, for mud/sand, seagrass as well as deep water were generated based-on in-situ observations. The overall classification accuracy with the interaction of inter-classes is demonstrated in Table 3.

Table 3. Confusion matrix for classification of coastal features with BRI on Landsat ETM+ using MLC. The training samples set of an individual class derived from in-situ data were assigned for classifying the BRI layer.

\begin{tabular}{lcccc}
\hline $\begin{array}{c}\text { Classification } \\
\text { Data }\end{array}$ & \multicolumn{3}{c}{ Reference Data (Pixel) } & $\begin{array}{c}\text { User } \\
\text { Accuracy }\end{array}$ \\
\hline & Seagrass & Mud/Sand & $\begin{array}{c}\text { Row } \\
\text { Total }\end{array}$ & \\
\hline Landsat & & & & \\
ETM+ & & 12 & 76 & 84.15 \\
Seagrass & 64 & 67 & 85 & $78.8 \%$ \\
Mud/Sand & 36 & 79 & 161 & \\
Column total & 100 & $84.8 \%$ & & \\
$\begin{array}{l}\text { Producer } \\
\text { accuracy }\end{array}$ & $64.0 \%$ & & & \\
Overall & & & 55.45 & \\
accuracy & & & $\%$ & \\
Kappa & & & 0.5547 & \\
coefficient & & & & \\
\hline
\end{tabular}

The most suitable Landsat band, which demonstrated robust compliance between in-situ data and result of seagrass delineation is the blue and red band $\left(\mathrm{BRI}_{b, r}\right)$ combination. This evidence proved that the combination has higher accuracy (Table 3) when compared with $\mathrm{BRI}_{g, r}$ or $\mathrm{BRI}_{b, g}$. Before conducting such assessment, verification of in-situ data was implemented. The blue band demonstrated the most suitable band within shallow for detection of substrate feature precisely seagrass with changing density classes.

\subsection{Logistic Models used for Deriving Above-ground Seagrass Total Carbon Stock}

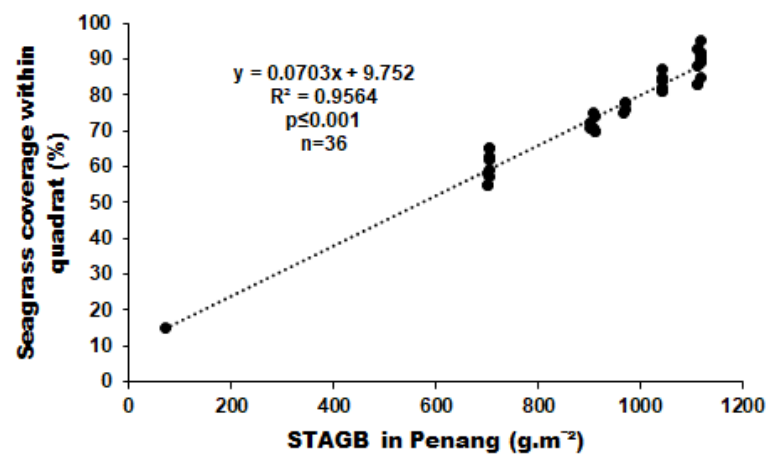

Figure 3. Correlation between STAGB acquired from in-situ measurement with the seagrass proportion of seagrass coverage in Penang.
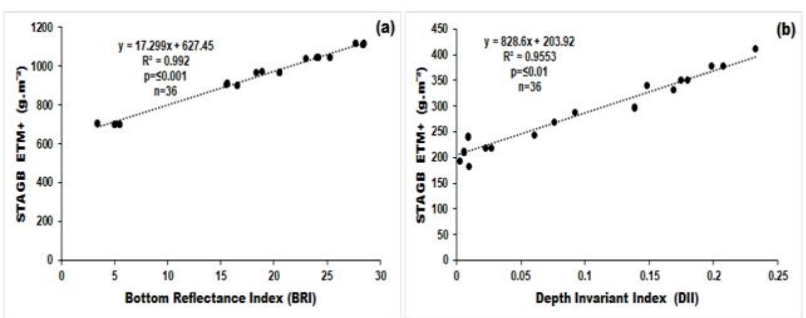

Figure 4. The established relationship between seagrass indexes with STAGB quantified empirically from the Landsat ETM+ imageries of a) STAGB vs BRI $\mathrm{b}_{\mathrm{b}}$ and b) STAGB against DII acquired after water column correction in 2017.

To perfectly reporting the results of STAGC within the study location, the relationship between STAGB attained from in-situ observation with the percentage of seagrass coverage was performed (see Figure 3). Similarly, ground-based in-situ measurement in STAGB and derived STAGB from BRI via prediction were compared. This process was also applied to DII for ensuring accuracy and comparing of the output (Figure 4). It connoted that $\mathrm{BRI}_{b}$ values are higher compared to DII that it is less than $1 \%$ of the BRI values attained from Landsat ETM+. These variations in proportion could be as results of the impact in-depth, which is only present in BRI model, even though the DII model has no depth variable. Additionally, it gives the impression that STAGC quantified from RS-based data overcalculated the biomass matrices when compared with the manual STAGB measurement. Figure 5 shows the coefficient determination of $\mathrm{R}^{2}$ obtained through establishing a relationship between STAGB ground-based measurements against STAGB estimated via Landsat ETM+. Therefore, $\mathrm{R}^{2} 0.99$ and 0.98 , with respective RMSE +-0.90 g.m- ${ }^{2}$ and +- 0.62 g.m- ${ }^{2}$ for only $30 \mathrm{~m}$ pixel resolution were realised. 

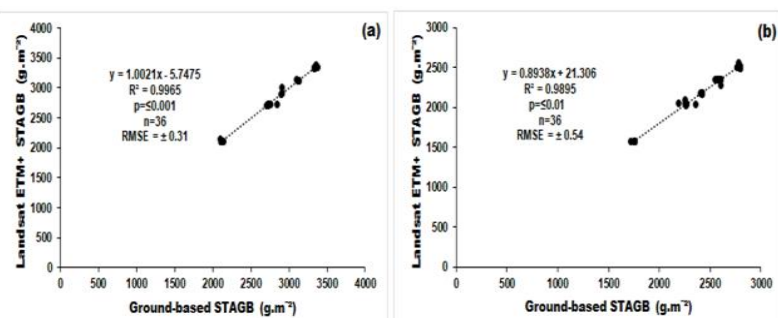

Figure 5. The in-situ-based seagrass biomass versus satellitebased estimation in the corresponding point locations using 36 inductive sites as well as 36 deductive sites.

Individual single plotted marker denotes seagrass sampling quadrats selected by $0.5 \times 0.5 \mathrm{~m}$ scale, which were up-scaled to the size of $30 \times 30 \mathrm{~m}$ Landsat pixel. Table 4 shows the logistic models employed to establish an association between STAGB against BRI and STAGB versus DII obtained both from ETM+. In this regards, the most suitable logistic model was used for the STAGB estimation.

Table 4. Logistic models established on STAGB versus BRI and STAGB against DII acquired with Landsat ETM+.

\begin{tabular}{|c|c|c|c|}
\hline State & $\begin{array}{l}\text { Regression } \\
\text { Model }\end{array}$ & Equation & $\mathbf{R}^{2}$ \\
\hline \multirow[t]{5}{*}{$\begin{array}{l}\text { Penang } \\
\text { BRI }\end{array}$} & Exponential $* *$ & $\begin{array}{l}\text { STAGB }= \\
651.97 \mathrm{e}^{0.0194(\mathrm{BRI})}\end{array}$ & 0.986 \\
\hline & Linear $* * *$ & $\begin{array}{l}\text { STAGB }=17.299 \mathrm{BRI}+ \\
627.45\end{array}$ & 0.992 \\
\hline & Logarithmic ** & $\begin{array}{l}\text { STAGB }= \\
208.26 \ln (B R I)+ \\
379.87\end{array}$ & 0.934 \\
\hline & $\begin{array}{l}\text { Polynomial } \\
\text { (second-order) } *\end{array}$ & $\begin{array}{l}\text { STAGB }= \\
0.0229 \mathrm{BRI}^{2}+ \\
18.042 \mathrm{BRI}+623.32\end{array}$ & 0.992 \\
\hline & Power * & $\begin{array}{l}\text { STAGB }= \\
489.31 \mathrm{BRI}^{0.2372}\end{array}$ & 0.956 \\
\hline \multirow[t]{5}{*}{$\begin{array}{l}\text { Penang } \\
\text { DII }\end{array}$} & Exponential $* * *$ & $\begin{array}{l}\text { STAGB }= \\
207.53 \mathrm{e}^{2.9386 x(\mathrm{DII})}\end{array}$ & 0.942 \\
\hline & Linear $* *$ & $\begin{array}{l}\text { STAGB }=828.6 \mathrm{DII}+ \\
203.92\end{array}$ & 0.955 \\
\hline & Logarithmic $* *$ & $\begin{array}{l}\text { STAGB }= \\
39.617 \ln (\mathrm{DII})+405.48\end{array}$ & 0.799 \\
\hline & $\begin{array}{l}\text { Polynomial } \\
\text { (second-order) } *\end{array}$ & $\begin{array}{l}\mathrm{STAGB}=1173.2 \mathrm{DII}^{2}+ \\
590.81 \mathrm{DII}+208.23\end{array}$ & 0.960 \\
\hline & Power * & $\begin{array}{l}\text { STAGB }= \\
429.57 \mathrm{DII}^{0.1444}\end{array}$ & 0.833 \\
\hline
\end{tabular}

Note: significant levels: $* p \leq 0.05 ; * * p \leq 0.01 ; * * * p \leq 0.001$. In the selection of the best applicable logistic model to quantify STAGC, determination of coefficient via regression analysis was applied as per the prime indicator. Thus, several logistic models were used on the Landsat images, where the linear model was found the most suitable in deriving STAGC contents in the study location. The linear model employed in both images of BRI and DII can be expressed as follows:

$$
\mathrm{STAGB}=17.299 \mathrm{BRI}+627.45
$$

where $a)=17.299 ;$ and b) $627.45=0.986$.

$$
\text { STAGB }=828.6 \mathrm{DII}+203.92
$$

As the model $\left(\mathrm{R}^{2}\right)$, coefficient correlation demonstrated a high percentage of relationship with BRI $\left(\mathrm{R}^{2} 0.986\right)$ on the satellitebased image after processing, compared with the DII, which revealed $\mathrm{R}^{2}=0.955$. The STAGC estimate from seagrass meadow is regarded as suitable with Landsat 7 ETM+ of $30 \mathrm{~m}$ resolution. Therefore, the results of this study and some reported publications on seagrass biomass mapping and estimation (Hashim, et al., 2014; Misbari and Hashim, 2016; Sagawa, et al., 2010), it can be revealed that Landsat 7 with a high radiometric-resolution possess an excellent compliance using BRI than DII for estimating STAGC.

\subsection{Mapping and Estimation of Seagrass Blue Carbon Aboveground Carbon Component}

Blue carbon component is regarded as a pool where carbon is captured and, which are usually documented in MtC $/ \mathrm{ha}^{1}$ in a specific carbon pool (Kroeger, et al., 2017). The determination of carbon contents in the STAGC were realised after selecting the most suitable association between STAGB against $\mathrm{BRI}_{b}$ and STAGB versus $\mathrm{DII}_{b}$. These developed models (linear regression) were applied through band-mask on the satellite image for obtaining the STAGB. Similarly, to derive the STAGC contents, a conversion factor of 0.34 was utilised (Sani et al., 2019).

The STAGC mapping of Penang Straits was achieved (Figure 6), $\mathrm{BRI}_{b}$ pixels were summed to 191,928 , and where for a single pixel is $900 \mathrm{~m}^{2}$. This pixels proportion resulted in the realisation of the total area of 17,273.52ha covered by STAGC. The amounted carbon confirmed that the STAGC derived from BRI image is higher than the contents obtained using DII image, as shown in Table 5 (the estimation of STAGC with BRI recorded $80 \%$ while, DII $20 \%$ carbon contents ). These differences in carbon contents from the two models (Figure 7) can be because of the depth values that exist only in BRI. These depth values enable the BRI to be applied for detecting submerged seagrass species in both clear (type A) and less clear water (type B).

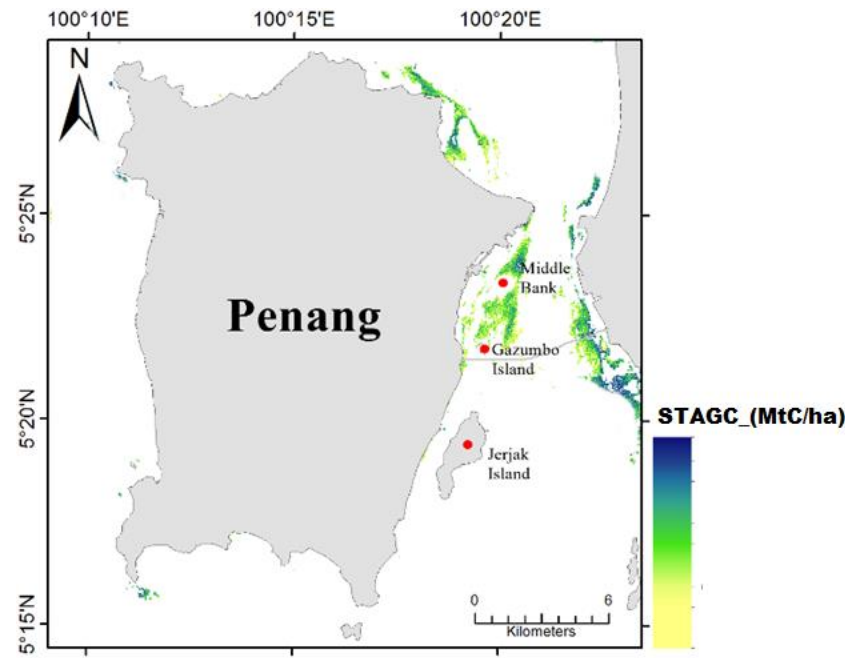

Figure 6 . The total aboveground seagrass blue carbon spatial extent in Penang coastline.

where a) $=828.6$; and b) $203.92=0.955$. 
Table 5. The proportion of STAGC of both western and eastern

\begin{tabular}{ccccc}
$\begin{array}{c}\text { Model } \\
\text { type }\end{array}$ & $\begin{array}{c}\text { Seagrass } \\
\text { total area } \\
\text { (ha) }\end{array}$ & $\begin{array}{c}\text { Carbon } \\
\text { stock } \\
\left(\mathbf{M t C}_{\mathbf{h a}} \mathbf{1}^{\mathbf{1}}\right)\end{array}$ & $\begin{array}{c}\text { STAGC } \\
(\boldsymbol{\%}) \text { out of } \\
\text { STAGB }\end{array}$ & $\begin{array}{c}\text { Accuracy } \\
\text { assessment } \\
(\text { RMSE) }\end{array}$ \\
\hline BRI & $17,273.52$ & 0.44 & 0.45 & +-0.31 \\
DII & $17,273.52$ & 0.11 & 0.35 & +-0.54 \\
\hline
\end{tabular}

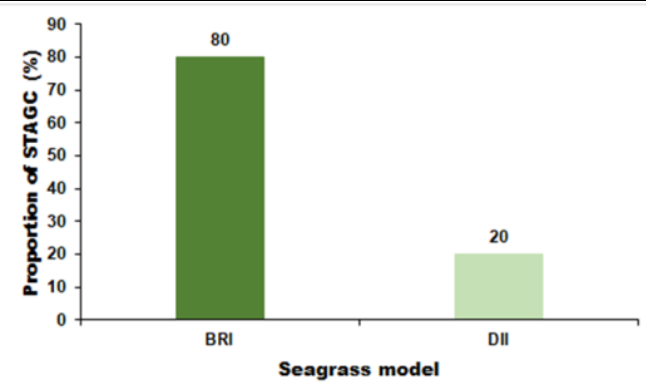

Figure 5. The differences between the proportions of STAGC estimated using BRI and the other with DII model.

As revealed earlier, the bands blue and red were employed in this study was due to the better capability of the blue band in penetrating water when compared with other bands. Whereas, the green band functionality is similar to that of the blue band, not as excellent as a blue band. This study is, therefore, essential to convey substantial impacts to four key sectors such as society, related industry, economy and environment. It will be vital to the inhabitant of coastal environment who solemnly relied on the coastal resources comprising mangrove forest, fisheries. Similarly, the coastal management authority could adopt this study on issues related to the coastal environment as well as the marine life biodiversity. To know how to tackled ocean health and food security.

Furthermore, it will assist in making a critical decision by related industry such as 'National Department of Fisheries Board', principally on fish abundance within seagrass species along the coastline of Penang. Economically, fisheries, tourism, and aquaculture activities will be benefited from this study, as they significantly relied on coastal health. Hence, reinstating the ocean resilience via protection of seagrass spatial extents and STAGC is the focal point of this study. Generally, adapting these results as measures will assist in fast-tracking the realisation of targets 14.2, 14.5 of United Nations sustainable development Goal $14^{\text {th }}$, which is scheduled to be terminated in the year 2020 .

\subsection{Accuracy Assessment}

Several accuracy assessments were conducted to ensure precise mapping and estimation of STAGC. The statistical assessments include RMSE applied to confirm the agreement between insitu STAGB and the predicted STAGB. Whereas the overall accuracy of intertidal and submerged seagrass detection on $30 \mathrm{~m}$ resolution of Landsat ETM+ was conducted, both user's and producer's accuracy of seagrass were also applied (Table 3). STAGB correlated with in-situ seagrass coverage within the quadrat was reported. Also, for more conformation of the accuracy, t-test and khat statistic were observed (Table 6).

\begin{tabular}{clc}
\hline Area & Khat statistic & t-test \\
\hline Penang & 0.15 & $\leq 0.01$ \\
\hline
\end{tabular}

Table 6. Accuracy assessment of seagrass

\section{CONCLUSIONS}

This study has effectively used satellite-based RS to demonstrate the mapping and estimation of STAGC by using a suitable logistic model and processing methods in a complex seagrass habitat. The robustness of DII and BRI on a Landsat ETM+ imagery is confirmed. BRI and DII images were used to allow the mapping of seagrass spatial distribution and estimation of STAGC contents of the study area. The estimate realised by the seagrass retrieval models (BRI and DII) were compared for more precise STAGC measurement. Information on sea truth was employed for training datasets used in the MLC and validation of the features. Consequently, this study is needed, as to provide initiatives for STAGC mapping and quantification within the coastline of Penang state. The results provided by this study will assist in coastal management as it gives awareness on STAGC dynamics, which can help speed up the realisation of SDGs' targets 14.2 and 14.5 of the United Nations.

\section{ACKNOWLEDGEMENTS}

The authors acknowledge the study facilities utilised from Universiti Teknologi Malaysia. The grant support by MOHE grants on Blue Carbon Seagrass Mapping through Remote Sensing (R.J130000.7809.4F854); as well as HABs Physiological Ecology Identification using Multi-mission satellite observations (R.J130000.7809.4L851). Moreover, the authors wish to show their gratitude to the Nigerian federal government for giving to the lead author a financial intervention via the Tertiary Education Trust Fund (TETFUND).

\section{REFERENCES}

Bukata, R. P., Jerome, J. H., Kondratyev, A. S. and Pozdnyakov, D. V. 2018: Optical properties and remote sensing of inland and coastal waters. CRC press.

Hashim, M., Misbari, S., Yahya, N. N., Ahmad, S., Reba, M. N. and Komatsu, T. 2014: An approach for quantification of submerged seagrass biomass in shallow turbid coastal waters. Proceedings of the 2014 Geoscience and Remote Sensing Symposium (IGARSS), 2014 IEEE International: IEEE, 44394442 .

Hossain, M., Bujang, J., Zakaria, M. and Hashim, M. 2015: The application of remote sensing to seagrass ecosystems: an overview and future research prospects. International Journal of Remote Sensing. 36(1), 61-114.

Klemas, V. 2013a: Remote sensing of coastal wetland biomass: An overview. Journal of Coastal Research. 29(5), 1016-1028.

Klemas, V. 2013b: Remote sensing of emergent and submerged wetlands: an overview. International journal of remote sensing. 34(18), 6286-6320.

Kovacs, E., Roelfsema, C., Lyons, M., Zhao, S. and Phinn, S. 2018: Seagrass habitat mapping: how do Landsat 8 OLI, Sentinel-2, ZY-3A, and Worldview-3 perform? Remote Sensing Letters. 9(7), 686-695. 
Kroeger, K. D., Crooks, S., Moseman-Valtierra, S. and Tang, J. 2017: Restoring tides to reduce methane emissions in impounded wetlands: A new and potent Blue Carbon climate change intervention. Scientific reports. 7(1), 11914.

Lyons, M., Phinn, S. and Roelfsema, C. 2011: Integrating Quickbird multi-spectral satellite and field data: mapping bathymetry, seagrass cover, seagrass species and change in Moreton Bay, Australia in 2004 and 2007. Remote Sensing. $3(1), 42-64$

Lyzenga, D. R. 1978: Passive remote sensing techniques for mapping water depth and bottom features. Applied optics. 17(3), 379-383.

Lyzenga, D. R. 1981: Remote sensing of bottom reflectance and water attenuation parameters in shallow water using aircraft and Landsat data. International journal of remote sensing. 2(1), 7182.

Maritorena, S. 1996: Remote sensing of the water attenuation in coral reefs: a case study in French Polynesia. International Journal of Remote Sensing. 17(1), 155-166.

Misbari, S. and Hashim, M. 2014: Evaluation of median filtering impact on satellite-based submerged seagrass mapping accuracy in tropical coastal water. Proceedings of the 2014 Proceedings of 35th Asian Conference on Remote Sensing, Myanmar,

Misbari, S. and Hashim, M. 2016: Change detection of submerged seagrass biomass in shallow coastal water. Remote Sensing. 8(3), 200

Poursanidis, D., Topouzelis, K. and Chrysoulakis, N. 2018: Mapping coastal marine habitats and delineating the deep limits of the Neptune's seagrass meadows using very high resolution Earth observation data. International Journal of Remote Sensing. 1-18.

Sagawa, T., Boisnier, E., Komatsu, T., Mustapha, K. B., Hattour, A., Kosaka, N. and Miyazaki, S. 2010: Using bottom surface reflectance to map coastal marine areas: a new application method for Lyzenga's model. International Journal of Remote Sensing. 31(12), 3051-3064.

Sani, D. A. and Hashim, M. 2018: A preliminary work on blue carbon stock mapping in mangrove habitat using satellite-based approach. Proceedings of the 2018 IOP Conference Series: Earth and Environmental Science: IOP Publishing, 012078.

Sani, D. A., Hashim, M. and Hossain, M. S. 2019: Recent advancement on estimation of blue carbon biomass using satellite-based approach. International Journal of Remote Sensing. 1-37.

Tan, K. S., Acerbi, E. and Lauro, F. M. 2016: Marine habitats and biodiversity of Singapore's coastal waters: A review. Regional Studies in Marine Science. 8, 340-352.

Traganos, D., Aggarwal, B., Poursanidis, D., Topouzelis, K., Chrysoulakis, N. and Reinartz, P. 2018). Towards global-scale seagrass mapping and monitoring using Sentinel-2 on Google Earth Engine: The Case study of the Aegean and Ionian Seas. Remote Sensing. 10(8), 1227.
Revised August 2019 